\title{
Simultaneous biohydrogen production and purification in a double-membrane bioreactor system
}

ARTICLE in INTERNATIONAL JOURNAL OF HYDROGEN ENERGY · JANUARY 2015

Impact Factor: 2.93 · DOI: 10.1016/j.ijhydene.2014.12.002

CITATIONS

3

DOWNLOADS

61
VIEWS

63

6 AUTHORS, INCLUDING:

\section{Péter Bakonyi}

University of Pannonia, Veszprém

26 PUBLICATIONS 98 CITATIONS

SEE PROFILE

\section{Germán Buitrón}

Universidad Nacional Autónoma de México 101 PUBLICATIONS 855 CITATIONS

SEE PROFILE
Nándor Nemestóthy

University of Pannonia, Veszprém

48 PUBLICATIONS 380 CITATIONS

SEE PROFILE

Katalin Bélafi-Bakó

University of Pannonia, Veszprém

90 PUBLICATIONS 920 CITATIONS

SEE PROFILE 


\title{
Simultaneous biohydrogen production and purification in a double-membrane bioreactor system
}

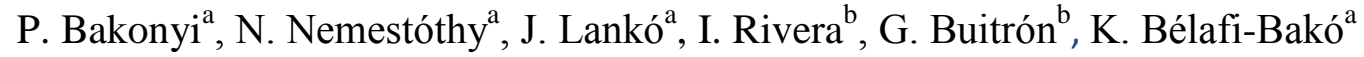

${ }^{\mathrm{a}}$ : Research Institute on Bioengineering, Membrane Technology and Energetics, University of Pannonia, Egyetem ut 10, 8200 Veszprém, Hungary

${ }^{\mathrm{b}}$ : Laboratory for Research on Advanced Processes for Water Treatment, Instituto de Ingeniería, Unidad Académica Juriquilla, Universidad Nacional Autónoma de México, Blvd. Juriquilla 3001, Querétaro 76230, México

*Corresponding Author: Peter Bakonyi

$$
\begin{gathered}
\text { Tel: }+3688624385 \\
\text { Fax: }+3688624292
\end{gathered}
$$

E-mail: bakonyip@almos.uni-pannon.hu 


\begin{abstract}
In this work the establishment of a double-membrane bioreactor was aimed. Initially, a continuous hydrogen fermenter was coupled with a commercial Kubota ${ }^{\circledR}$ microfiltration membrane module and the production performance of the cell-retentive design was evaluated under various hydraulic retention times. As a result, it has been observed that altering HRT influenced the rejection feature of the microfiltration module while had an inverse effect on hydrogen productivity and yield, since shortened HRTs were accompanied by gradually decreasing $\mathrm{H}_{2}$ yields (HY) and progressively increasing volumetric $\mathrm{H}_{2}$ production rates (HPR). The highest HY and HPR were achieved as $1.13 \mathrm{~mol} \mathrm{H}_{2} / \mathrm{mol}$ glucose and $0.24 \mathrm{~mol}$ $\mathrm{H}_{2} / \mathrm{L}$-d, respectively. Furthermore, a Permselect ${ }^{\circledR}$ (PDMS) gas separation membrane was installed to the anaerobic membrane bioreactor and its ability to separate hydrogen from the raw fermentation gaseous mixture was assessed. The highest purity hydrogen obtained in onestep purification by the PDMS module was 67.3 vol.\%, which exceeds $30 \%$ enrichment efficiency considering $51.3 \mathrm{vol}_{\%} \mathrm{H}_{2}$ in the feed gas. Hence, it could be concluded that the poly(dimethyl siloxane) membrane has potential to attractively concentrate biohydrogen from fermenter off-gas and may be used for in-situ product recovery.
\end{abstract}

Keywords: biohydrogen, membrane bioreactor, gas separation, integrated system, PDMS 


\section{Introduction}

The design and initiation of bioreactors is a crucial element of continuous dark fermentative hydrogen production [1,2]. Recently, fermenters attached with membranes have been demonstrated as highly attractive reactor configurations to achieve intensified microbiological hydrogen generation [3]. Membranes coupled to hydrogen forming reactors can potentially serve two-fold but equally important purposes. On one hand, pressure driven membrane processes such as microfiltration can be employed to enrich hydrogen generating whole cell biocatalysts and thus accomplish intensified $\mathrm{H}_{2}$ formation as compared to traditional free-cell applications, e.g. CSTRs. On the other hand, membranes i.e. gas separation modules may provide a sufficient way to purify hydrogen in order to obtain concentrated biohydrogen applicable for fuel cells [4].

Conventional anaerobic hydrogen producing bioreactors using porous liquid filtration membranes provide the chance to maintain separate hydraulic- and solid retention times. This is an important trait since it has turned out that decoupled and altered sludge retention times (SRT) could be responsible for remarkable shifts in the hydrogen evolving microbial consortia and the related gas production values [5]. Furthermore, Lee et al. [6] have reported that attaching microfiltration membrane module to continuous hydrogen fermenter could improve the efficacy of the process. The results indicated notable enhancement in the volumetric production rates and hydrogen yields, which could be attributed to the enriched biomass of active whole cell biocatalysts. It has also appeared that peak values of $\mathrm{H}_{2}$ productivity and yield took place under different reactor operation. In another relevant study [7] CSTR and MBR arrangements were compared for biotechnological hydrogen production, when operated with various organic loading intensities. The outcomes were somewhat beyond the preliminary expectations since the integrated membrane bioreactor operation did not provide advantages over the conventional suspended free-cell reactor in terms of hydrogen yield. Nevertheless, the performance of the anaerobic membrane bioreactor could apparently exceed that of its traditional counterpart in the view of $\mathrm{H}_{2}$ evolution rate by approximately $50 \%$ under certain experimental sets. Additionally, Lee et al. [8] assessed the feasibility of MBR and CSTR configurations for biological hydrogen production. The final conclusion of the long-term, steady-state measurements was that the achievable $\mathrm{H}_{2}$ yields in both reactor set-ups were quite comparable, while on the other hand, MBR took the advantage from the point of view of volumetric hydrogen generation rate, which was approximately 2.6 times 
higher than in the CSTR. The same group of scientists expanded their research on AnHPMBR (anaerobic hydrogen producing membrane bioreactor) under various solid retention times [9]. It was obvious from the results that the extremely high solid retention time as long as 90 days remarkably decreased both hydrogen productivity and yield. This behavior was associated with the increasing amount of extracellular polymeric substances (EPS) under longer SRT. It was elucidated that EPS, as secondary products of fermentation process - depending on their concentrations - are potential inhibitors of microbiological hydrogen formation. Recently, Kim et al. [10] comparatively assessed the $\mathrm{H}_{2}$ production performances of anaerobic membrane bioreactor and completely stirred tank reactor. The critical evaluation of the tentative results obtained demonstrated that AnMBR design was far more viable to get better $\mathrm{H}_{2}$ productivities and yields. In the optimized conditions of the MBR, the increase of $\mathrm{H}_{2}$ yield was about $50 \%$ whilst hydrogen production rate has been more than doubled in comparison to the conventional continuous reactor.

Besides the traditional AnMBR arrangement relying on porous water filtration membrane modules, MBRs integrated with gas separation seem also attractive designs to enhance the feasibility of dark fermentative hydrogen production [4,11]. The concept of such systems is the in-situ recovery and purification of biologically formed hydrogen from the fermenter off-gas - containing notable amount of $\mathrm{CO}_{2}$ beyond $\mathrm{H}_{2}$ - in a way that it may be directly utilized in fuel cells. Moreover, the instant and continuous extraction of hydrogen helps to keep lowered hydrogen partial pressure in the reactor which has been proven advantageous for higher hydrogen production yields [11]. The separation of hydrogen from complex biological gas mixtures is a challenging task because several compounds, such as carbon dioxide, hydrogen sulfide, water vapor, etc. pose a threat to achieve the required enrichment efficiency [4]. Recently, our group has tested a range of gas purification membranes made of different materials such as polyimide, SAPO 34 and silicone for fermentative hydrogen concentration, using binary $\left(\mathrm{H}_{2} / \mathrm{CO}_{2}\right)$ mixtures [11,12]. Regardless of the membrane module, it could be concluded that the composition of the feed gas is a key factor to be considered. However, in those previous experiments, the membranes were applied separately from the hydrogen fermenter and therefore, not much is known yet about their ability to deal with complex, raw fermentation gaseous mixtures containing the valuable component, biohydrogen.

In this investigation, a double-membrane bioreactor system was aimed to establish. Firstly, the performance of anaerobic hydrogen producing membrane bioreactor employing 
microfiltration liquid filtration membrane module was focused under different hydraulic retention times. Afterwards, this conventional AnHPMBR was installed with a PDMS membrane and the behavior of the module was evaluated with raw headspace gas mixture at certain operating circumstances. The novelty of the work is that this is the first time report when a single device - a double-membrane bioreactor - applying two kinds of membranes concerns both the upstream and downstream aspects of microbiological hydrogen generation and biohydrogen is directly enriched from untreated reactor off-gas during continuous operation.

\section{Materials and Methods}

\subsection{Hydrogen production measurements in AnMBR}

A double-wall, laboratory scale device was used to construct the hydrogen producing anaerobic membrane bioreactor. The vessel of the reactor was made of borosilicate glass and had a nominal total volume of $3.5 \mathrm{~L}$. To start-up the continuous reactor, $1.5 \mathrm{~L}$ of anaerobic digester sludge - receiving preliminary heat-treatment in water bath under the circumstances $\left(75{ }^{\circ} \mathrm{C}, 30 \mathrm{~min}\right.$ ) found favorable in our previous paper [13] - was filled in. Afterwards, $0.5 \mathrm{~L}$ of feed solution comprising glucose and yeast extract (dissolved in dechlorinated tap water) was added to the pretreated sludge. The concentration of glucose and yeast extract in the feed solution was $40 \mathrm{~g} \mathrm{~L}^{-1}$ and $10 \mathrm{~g} \mathrm{~L}^{-1}$, respectively. As the next step, $\mathrm{pH}$ of the broth was adjusted and automatically maintained at $5.5 \pm 0.2$ by means of $5 \mathrm{M}$ sulfuric acid and $\mathrm{NaOH}$ solutions. After setting $\mathrm{pH}$, the bioreactor was closed and purged for 20 minutes with 99.9\% $\mathrm{N}_{2}$ at a flow rate of approximately $5 \mathrm{~L} \mathrm{~min}^{-1}$ to create fully anaerobic conditions. Thereafter, the system was left as a batch for 24 hours. Stirring rate at $100 \mathrm{rpm}$ was provided by mixer equipped with 2 Rushton turbines. The bioreactor was placed in a constant $\left(25 \pm 1{ }^{\circ} \mathrm{C}\right)$ temperature room, while fermentation temperature was kept at $37 \pm 0.1{ }^{\circ} \mathrm{C}$ by circulating water in the double jacket reactor body. At the beginning of the $2^{\text {nd }}$ day, a plate-flame type microfiltration membrane module (Kubota Co., Japan) with an effective surface area of 0.1 $\mathrm{m}^{2}$ and pore size of $0.45 \mu \mathrm{m}$ was attached to the fermenter in an external-loop arrangement. At that point, the bioreactor system has started to run in fed-batch mode for 4 days, when 250 $\mathrm{mL}$ of fresh feed solution was supplemented in every 24 hours. The purpose of this step was to acclimatize the hydrogen producing microorganisms well to the environmental conditions 
and to gain higher cell densities. During the 4 days long fed-batch operation there was no spent media withdrawal, but the fermentation liquor was continuously circulated $(100 \mathrm{~mL}$ $\min ^{-1}$ ) on feed side of the Kubota membrane module without any permeate taken away. As a result of the fed-batch operation, the working volume in the reactor has been increased from the initial $2 \mathrm{~L}$ to $3 \mathrm{~L}$.

On the $6^{\text {th }}$ day, the AnMBR was switched to continuous mode with gradually decreasing HRT values of $92 \mathrm{~h}, 48 \mathrm{~h}, 24 \mathrm{~h}$ and $12 \mathrm{~h}$. A new HRT was adjusted only after the reactor ran under steady-state conditions at least 5 times longer than the respective hydraulic retention time. In this work, steady-state of the bioreactor was considered when fluctuations of volumetric hydrogen gas production rate and hydrogen yield were less than $10 \%$ on daily average basis. In the course of the measurements, the bioreactor was not restarted (emptied, cleaned and refilled) after each stage (HRT) of continuous operation, the soluble metabolic products were constantly removed in the fermentation effluent with permeate of Kubota ${ }^{\circledR}$ membrane.

To maintain the HRT needed, the volume of broth drawn as permeate was continuously replaced with equal portion of fresh feed solution. Permeate- and feed flows were controlled by a peristaltic pump (Masterflex ${ }^{\circledR}$, Cole-Parmer Instrument Co.). For the continuous operation in AnMBR, the influent composition was modified as follows: glucose $65 \mathrm{~g} \mathrm{~L}^{-1}$, yeast extract $-2.5 \mathrm{~g} \mathrm{~L}^{-1}$. Throughout the experiments, the solid retention time (SRT) was fixed as 10 days. To ensure SRT of 10 days, appropriate amount of fermentation liquor was manually removed from the bioreactor every day once and substituted with equal amount of fresh water. The SRT was defined as the ratio of total working volume $(\mathrm{V}, \mathrm{L})$ and the volume of medium daily taken from the bioreactor $\left(\mathrm{Q}_{\mathrm{d}}, \mathrm{L} \mathrm{d} \mathrm{d}^{-1}\right)$, SRT $=\mathrm{V} \mathrm{Q}_{\mathrm{d}}^{-1}$. The feed solution used was non-sterilized and introduced to the bioreactor from a substrate tank placed in a refrigerator at $4.0 \pm 0.5{ }^{\circ} \mathrm{C}$. Retentate of the microfiltration module has fully returned to the fermenter with a flow rate of $100 \mathrm{~mL} \mathrm{~min}^{-1}$.

The volume of the developing biological gas was measured by a gas counter and the data were recorded via an application written in Labview software. The $\mathrm{H}_{2}$ content of the headspace gas was real time monitored by BlueSens ${ }^{\circledR}$ (BlueSens Gas Sensor GmbH, Germany) gas sensor, as detailed in our earlier publication [14]. $\mathrm{CO}_{2}$ was manually checked by gas chromatography, as described in Section 2.2. The volume of hydrogen (L) produced was calculated according to the equation given in our previous article [15] and corresponds to $37{ }^{\circ} \mathrm{C}$ and 1 bar(a). Liters of hydrogen fermented were converted into moles and hydrogen 
productivity values are given as mol $\mathrm{H}_{2} \mathrm{LWv}_{\mathrm{Wv}}^{-1} \mathrm{~d}^{-1}$, where $\mathrm{L}_{\mathrm{Wv}}$ is the working volume of the

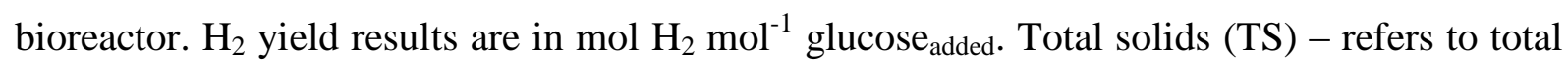
dry matter - contents were followed in accordance with APHA [16]. TS data presented in Fig. 3 are mathematical averages or triplicate measurements, standard deviation was $<5 \%$.

TS rejection was estimated as follows: $\left(\mathrm{C}_{T S}{ }^{\mathrm{R}}-\mathrm{C}_{\mathrm{TS}}{ }^{\mathrm{P}}\right) / \mathrm{C}_{\mathrm{TS}}{ }^{\mathrm{R}}$, where $\mathrm{C}_{\mathrm{TS}}{ }^{\mathrm{R}}$ and $\mathrm{C}_{\mathrm{TS}}{ }^{\mathrm{P}}$ is the TS concentration in the bioreactor (retentate) and permeate, respectively. TS concentration and TS rejection data for bioreactor operation at $\mathrm{HRT}=12 \mathrm{~h}$ are not reported due to technical issues.

\subsection{Membrane separation tests}

For biohydrogen separation tests, a dense (non-porous) PDMS membrane module (MedArray Inc., product reference: PDMSXA-10) was applied in cross-flow design. The module housing is made of polycarbonate and contains silicone hollow-fibers with an available surface area of $10 \mathrm{~cm}^{2}$. To conduct the gas purification experiments, off-gas of steady-state fermenter (HRT=92 h) was uninterruptedly collected in $30 \mathrm{~L}$ gas bag, which served as a temporary storage buffer. Between the fermenter and the gas balloon, a check (one-way) valve was built-in.

The fermenter gas composition may be changed by time even under steady-state conditions due to uncertainties of microbiological side. This can be a notable issue since membrane performance is not independent of the feed gas quality. Therefore, to restrict significant alterations in feed gas stream composition and ensure more stable inlet, a buffer container (the above-mentioned $30 \mathrm{~L}$ gas bag) was employed prior to delivering the gas to the membrane. According to the experiences, the intermediary storage tank - working as a homogenizer - was able to smooth the random and sudden changes occurred in feed gas composition. Calculation of component permeabilities was done by considering average feed gas composition (51.3 vol.\% $\mathrm{H}_{2}, 47.0$ vol.\% $\mathrm{CO}_{2}, 1.7$ vol.\% undefined background compounds) at HRT=92 h. During the gas permeation measurements, deviations of gas concentrations in the feed remained under $2 \%$ relatively to the mean values given above, respectively. It is important to note that the fermenter off-gas is saturated with water at the temperature of the bioreaction $\left(37^{\circ} \mathrm{C}\right)$. However, as noted already, the membrane bioreactor was placed in a $25{ }^{\circ} \mathrm{C}$ constant temperature room. Hence, the excess amount of water vapor present in the raw gas - due to cooling from fermentation temperature to controlled room 
(being identical to gas separation) temperature - was removed prior to reaching the gas collection bag in order to avoid condensation on the membrane surface.

When 20 L raw gas was gained, continuous suction from the balloon has started by a peristaltic pump (Masterflex ${ }^{\circledR}$, Cole-Parmer Instrument Co.) and the gas was introduced into the membrane capillaries at a feed pressure of 3 bar(a). Total feed pressure was maintained by pressure regulator, which was placed between the delivery-side of the pump and the membrane feed side.

The connections between the membrane module and pressure regulator as well as the permeate- and retentate bubble flow meters were glass tubes, the fittings were made of Norprene $^{\circledR}$ material (Cole-Parmer Instrument Co.). The permeate side of the membrane was left under atmospheric pressure. The design of the membrane module allows the permeate to be drawn at two equally spaced point of the shell, however in our experiments the one being nearer to the feed spot was blocked and thus, permeate was only received closer to the retentate side.

To follow volumetric fluxes of permeate and retentate, glass-made soap film flowmeters and stopwatch were used.

To adjust so-called recovery - crucial parameter of membrane separation and defined as the ratio of retentate- and total feed flows - a stainless steel needle valve was placed on the retentate side between the membrane module and the film soap flowmeter. The scheme of the double-membrane bioreactor set-up can be seen in Fig. 1. Before executing the experimental runs, the integrity of the closed membrane system was checked and confirmed by overnight pressure (leak) tests carried out at 3 bar(a).

The $\mathrm{H}_{2}$ and $\mathrm{CO}_{2}$ concentrations of the feed (gas accumulated in the balloon), permeate and retentate streams were checked by gas chromatography as detailed in our earlier work [13]. Besides hydrogen and carbon dioxide, the GC was also calibrated for methane, however, its concentration was below the detectable level in all the experimental runs. The lack of observable methanogenic activity in this study is consistent with the previous findings reported for hydrogen producing anaerobic membrane bioreactors [3].

To calculate $\mathrm{CO}_{2} / \mathrm{H}_{2}$ selectivity, only the data refer to steady-state circumstances were taken into account. For membrane experiments, steady-state was assumed when the deviations in permeate and retentate fluxes and the related $\mathrm{H}_{2}$ and $\mathrm{CO}_{2}$ concentrations were below $1 \%$ for two consecutive sampling times. The sampling frequency for permeate and retentate was 4 $\mathrm{h}^{-1}$, while feed composition was determined twice an hour. Since the membrane bioreactor 
system was installed in a constant temperature room as mentioned in Section 2.1., the membrane separation performances obtained are valid at $25^{\circ} \mathrm{C}$.

Permeability values of $\mathrm{H}_{2}, \mathrm{CO}_{2}$ in Barrer $\left(1\right.$ Barrer $=10^{-10} \mathrm{~cm}^{3}(\mathrm{STP}) \mathrm{cm} \mathrm{cm}^{-2} \mathrm{~s}^{-1}$ $\mathrm{cmHg}^{-1}$ ) and practical separation selectivity of the membrane were computed according to the procedure described in our recent publication [11], except the estimation of the driving force, which was done here by Eq. 1 .

$$
\Delta p^{i}=0.5\left(P_{F} C_{F}^{i}+P_{R} C_{R}^{i}\right)-P_{P} C_{P}^{i}=0.5\left(p_{F}^{i}+p_{R}{ }^{i}\right)-p_{P}^{i} \quad \text { Eq. } 1
$$

where $\Delta \mathrm{p}^{\mathrm{i}}$ is the mean driving force for gas component " $\mathrm{i}$ " (cmHg), while $\mathrm{P}_{\mathrm{F}}, \mathrm{P}_{\mathrm{R}}$ and $P_{P}$ is the feed, retentate and permeate side total pressure $(\mathrm{cmHg})$, respectively. $\mathrm{C}_{\mathrm{F}}{ }^{\mathrm{i}}, \mathrm{C}_{R}{ }^{\mathrm{i}}$ and $\mathrm{C}_{\mathrm{P}}{ }^{\mathrm{i}}$ is designated as feed, retentate and permeate side volumetric concentration of gas component “i”, respectively. $p_{F}^{i}, p_{R}^{i}$ and $p_{P}^{i}$ is assigned as partial pressure of gas component " $i$ " on the feed, retentate and permeate side, respectively. For the calculation, $P_{R}=P_{F}$ was assumed.

Uncertainties of measurements can be attributed to various factors such as uncontrollable environmental conditions, observation, data recording, experimental design, etc. Therefore, identifying the overall experimental error due to the collective influences of the uncertainties - caused by different variables mentioned - is important. In this study, to verify the reliability of the gas separation measurements, mass balance for $\mathrm{H}_{2}$ and $\mathrm{CO}_{2}$ was calculated based on Eq. 2. Mass balance error ( $\left.\mathrm{E}_{\mathrm{MB}}, \%\right)$ was determined by Eq. 3.

$$
\mathrm{C}_{\mathrm{F}}^{\mathrm{i}} \mathrm{V}_{\mathrm{F}}=\mathrm{C}_{\mathrm{R}}^{\mathrm{i}} \mathrm{V}_{\mathrm{R}}+\mathrm{C}_{\mathrm{P}}^{\mathrm{i}} \mathrm{V}_{\mathrm{P}} \quad \text { Eq. } 2
$$

where $\mathrm{V}_{\mathrm{F}}, \mathrm{V}_{\mathrm{R}}$ and $\mathrm{V}_{\mathrm{P}}$ is the total volumetric flow rate $\left(\mathrm{mL} \min ^{-1}\right)$ of feed, retentate and permeate, respectively.

$$
\mathrm{E}_{\mathrm{MB}}=100\left[\mathrm{~V}_{\mathrm{F}}^{\mathrm{i}}-\left(\mathrm{V}_{\mathrm{R}}^{\mathrm{i}}+\mathrm{V}_{\mathrm{P}}^{\mathrm{i}}\right)\right] / \mathrm{V}_{\mathrm{F}}^{\mathrm{i}}
$$

where $V_{F}^{i}, V_{R}^{i}$ and $V_{P}^{i}$ is the partial volumetric flow rate $\left(\mathrm{ml} \mathrm{min}{ }^{-1}\right)$ of compound "i" in the feed, retentate and permeate, respectively. For all the membrane permeation tests conducted, $\mathrm{E}_{\mathrm{MB}}$ has not exceeded an acceptable level of $2 \%$. 


\section{Results and Discussion}

\subsection{Effect of hydraulic detention time on the performance of AnMBR}

It is well know that hydraulic retention time is a significant process variable of dark fermentative hydrogen production. In CSTR, the most common reactor configuration, the inappropriate adjustment of HRT may cause notable performance loss due to the wash out of the $\mathrm{H}_{2}$ producing bacteria. Furthermore, it is a drawback of CSTRs that they do not allow to achieve high cellmass concentrations, though it would be beneficial because the larger amount of active hydrogen evolving biomass in the bioreactor could result in better gas turnover rates. In other words, maintaining independent hydraulic and biomass (solid) residence times could be advantageous for the fermentation process, which can be attractively ensured by membranes [3]. Although HRT is a parameter to be taken into account, the optimal value to be applied is dependent on the specific characteristics of the bioreactor system, e.g. the inoculum and substrate used. For example, supposing an influent with a steady composition, the HRT will highly influence the substrate loading intensity of the reactor since feeding rate is directly proportional to the amount of organic material supplemented for the microorganisms in a certain period of time. If HRT is in the proper range, its increasing values can reportedly enhance the $\mathrm{H}_{2}$ production capacity [17].

Recently, it was demonstrated that SRT could have an opposite effect on hydrogen yield and volumetric productivity of anaerobic membrane bioreactor, since respective peak values occurred at distinct operational conditions [9]. Hence, it can be hypothesized that not only SRT but also HRT have such impact and therefore it may force a trade-off to get both acceptable $\mathrm{H}_{2}$ generation productivities and turnout. Thus, in our construction of AnMBR, the influence of HRT on these two process indicators was addressed. Four different HRT values between 92-12 hours were employed in a shortened order. The results illustrating the system response to the altered hydraulic residence times are depicted in Fig. 2.

As it can be concluded, in the range studied, $\mathrm{H}_{2}$ productivity showed an increasing trend with depressed HRT and a peak value of $0.24 \mathrm{~mol} \mathrm{H}_{2} \mathrm{LWv}^{-1} \mathrm{~d}^{-1}$ could be obtained at $\mathrm{HRT}=12 \mathrm{~h}$, which represents a more than two-fold increment in comparison with the one observed at the longest HRT value of $92 \mathrm{~h}$.

However, as for the hydrogen yields, a contrary behavior has appeared, leading to the finding that longer HRTs were preferable to receive more persuasive data. As it can be seen in 
Fig. 2, $\mathrm{H}_{2}$ yield peaked with $1.13 \mathrm{~mol} \mathrm{H}_{2} \mathrm{~mol}^{-1}$ glucose at HRT=92 h. This value is approximately three times higher than the one could be realized under the shortest HRT of 12 h.

As a summary, the analysis of Fig. 2 implies that better hydrogen productivities could be attained only at the sacrifice of hydrogen yields, and vice versa.

It was an important outcome of this work that no fouling of the microfiltration module took place in the course of the steady-state experiments lasting at least 5 times longer than the HRT adjusted, which is in agreement with the observations of other authors in the field working also with hydrogen producing anaerobic membrane bioreactors. For example, Lee et al. [6] reported that AnMBR could be operated for 20-30 times of the HRT without the occurrence of membrane fouling. Furthermore, Kim et al. [10] demonstrated the stability of the AnMBR system since no tough fouling issues were observed in any phase of the operation.

In addition, the influence of HRT of the filtration efficiency of the membrane module was evaluated by taking into account TS concentration in the bioreactor (retentate) and the effluent (permeate). Anaerobic membrane bioreactors are not only advantageous because of their reliable cell retention capabilities, but also because they generally provide a relatively clear spent media as compared to conventional CSTR applications. However, their effectiveness is substantially affected by the bioreactor operational regime such as hydraulic retention time [3]. According to Fig. 3, it seems that the TS rejection of the microfiltration membrane has decreased as the HRT was shortened. This might be ascribed to the fact that under shorter HRTs - having a fixed feed composition - more amount of substrate was introduced to the bioreactor resulting in higher volumetric organic loading rates. This increased substrate dosing increased the amount of soluble compounds in the reactor that are likely not rejectable by the microfiltration membrane due to its rather big pores. On the other hand, the microfiltration membrane was able to enrich larger size constituents of the fermentation liquor e.g. biomass. Nevertheless, according to the experimental results appearing in Fig. 3, it can be concluded that as the HRT was reduced, the gap between the bioreactor and the permeate total dry matter concentration has been lowered probably due to the increased amount of compounds insufficiently retained by the microporous membrane module. In this work, the performance of the microfiltration module under various HRTs was evaluated from TS point of view, however, experiments are planned in order to more comprehensively study the membrane behavior from other aspects such as COD retention, 
etc. In addition, it will be valuable to check the dynamics of microbial community and related volatile fatty acids profile under different HRT conditions. Based on this future information, it will be possible to describe the relationship between membrane characteristics, bacterial population diversity and hydrogen production efficiency.

\subsection{Biohydrogen separation from raw fermenter off-gas in integrated system}

The purity of biologically generated hydrogen is the major criteria for end-use technology, e.g. fuel cells or internal combustion engines $[18,19]$. The issue with biohydrogen is that it is not the sole gaseous product of the anaerobic bacteria living in the bioreactor and therefore it is diluted by energetically valueless compounds, mainly carbon dioxide. In addition, other impurities such as hydrogen sulfide, water vapor, etc. are also present, potentially affecting the membrane separation process $[4,11]$. The scope of the study on the integrated gas separation was to reveal the effectiveness of the PDMS membrane fed with unconditioned $\mathrm{H}_{2}$-containing gas mixture.

The bioreactor system combining the silicone membrane was realized under steadystate conditions of the AnMBR operating at HRT of $92 \mathrm{~h}$. The reason for choosing this particular setting of the hydrogen producing bioreactor was the gas handling capacity of the small-scale membrane. Preliminary permeation data (not shown) suggested that the membrane, due to its size and limited surface area, should be used under low gas production circumstances such as realized at the selected $92 \mathrm{~h}$ hydraulic retention time. Harmonizing the capacities of upstream and downstream stages is an important aspect of any process design, since a smooth operation favors the well-balanced relation of production and purification steps.

The silicone membrane used in this study belongs to the groups of rubbery materials and hence reflect $\mathrm{CO}_{2}$-selective features [20]. This means that permeability of carbon dioxide is theoretically higher than that of hydrogen and thus, $\mathrm{H}_{2}$ is to be enriched in the retentate fraction. The quality of concentrated hydrogen is highly dependent on the membrane operation, e.g. pressure, recovery, etc. [4]. In theory, the lower recovery - defined in Section 2.2. - can result in higher quality product, hydrogen. Therefore, in the integrated doublemembrane bioreactor application, membrane tests with three distinct recoveries were carried out. The $\mathrm{CO}_{2}$ and $\mathrm{H}_{2}$ concentrations attained under altered module operation are illustrated in Fig. 4. As it can be observed varying recovery (R/F) values significantly affected the steady- 
state compositions of both permeate and retentate streams. Attributed to the $\mathrm{CO}_{2}$-selective nature of silicone material, $\mathrm{CO}_{2}$ was concentrated always in the permeate irrespective of the experimental sets, while $\mathrm{H}_{2}$ was purified in the retentate. It is also to notice that $\mathrm{R} / \mathrm{F}$ demonstrated a reverse impact on $\mathrm{CO}_{2}$ and $\mathrm{H}_{2}$ transport, since increasing recovery resulted in higher $\mathrm{CO}_{2}$ concentrations in the permeate, while it was accompanied by lowered $\mathrm{H}_{2}$ concentrations of the retentate (Fig. 4). The permeabilities of gas molecules reflect how fast the gases are able to pass through the membrane and at the end differences between the individual values determine the quality of separation procedure. The permeabilities of $\mathrm{CO}_{2}$ and $\mathrm{H}_{2}$ gases are illustrated in Fig. 5, which suggest that the permeation rates of both compounds were functions of the recovery factor in a way that the higher the R/F is the greater $\mathrm{CO}_{2}$ and the lower $\mathrm{H}_{2}$ transmembrane permeation capability could be measured. Moreover, from the changes of permeability values it would also appear that $\mathrm{CO}_{2}$ migration was more notably influenced by the various recoveries and $\mathrm{H}_{2}$ permeability received less perturbation. The permeability values found for $\mathrm{CO}_{2}$ in this work is in good agreement with the values reported by Scholes et al. [21] for PDMS material under similar transmembrane pressure gradient and temperature.

The response of membrane purification quality to different operational range is presented in Fig. 6, where it is shown that enhanced selectivites were obtained when a higher portion of the feed flow was forced to the retentate and consequently, less quantity of permeate could be drawn. However, since the aim of the separation process is to ensure $\mathrm{H}_{2}$ in a more purified form, the membrane should be operated under lower R/F ratios, which can fulfill this criterion. As it can be seen in Fig. 4, the retentate contained 67.3 vol.\% hydrogen at lowest $\mathrm{R} / \mathrm{F}$ value of 0.34 , indicating that the membrane was able to enrich this gas by approximately $30 \%$ as compared to the initial (feed) gas mixture $\left(51.3 \mathrm{vol} . \% \mathrm{H}_{2}\right)$. It is assumed that the membrane gas upgrading system might provide better hydrogen concentration factor at even lower recoveries. In addition, it is an important feature of the process that hydrogen is concentrated in the retentate, which is an advantage since hydrogen remains in a pressurized form and hence there is no need for energetically unfavorable extra (re)compression in next technological steps e.g. another membrane for further $\mathrm{H}_{2}$ enrichment.

According to the results, it can be pointed out that the tiny, small bench-scale membrane was not capable of ensuring fuel cell-quality hydrogen under the conditions adjusted, but further improvement of the process e.g. cascade systems involving multiple stages with optimized process control might help to achieve it. 
Table 1 presents our current PDMS membrane performance in the view of others published earlier for hydrogen separation. As it can be seen in Table 1, the selectivity value in this study (Fig. 6) is not considerably different to the ones reported in the literature. However, it is to note that comparing the achievements should be made with care due to the unstandardized experimental conditions applied by different laboratory research groups. For example, Barillas and coworkers [22] demonstrated $\mathrm{CO}_{2} / \mathrm{H}_{2}$ selectivities of 3.5-3.7 for 3 PDMS membranes at $37{ }^{\circ} \mathrm{C}$ using a gas mixture consisting of $20 \mathrm{vol} . \% \mathrm{H}_{2}, 20$ vol. $\% \mathrm{CO}_{2}$ and Ar to balance. In another article, Merkel et al. [23] conducted gas permeation tests on PDMS membrane using syngas with a composition of 1.5 vol. $\% \mathrm{H}_{2} \mathrm{~S}, 10.5$ vol. $\% \mathrm{CO}_{2}, 46 \%$ vol.\% $\mathrm{CO}$, and $42 \%$ vol. $\% \mathrm{H}_{2}$. The mixed gas measurements yielded a $\mathrm{CO}_{2} / \mathrm{H}_{2}$ selectivity of 3.36 at $23{ }^{\circ} \mathrm{C}$. Moreover, in their study it has been shown that $\mathrm{H}_{2} \mathrm{~S}$ could be characterized by a $60 \%$ faster permeability relatively to $\mathrm{CO}_{2}$, supposing that PDMS membrane might be a suitable material to simultaneously remove $\mathrm{CO}_{2}$ and $\mathrm{H}_{2} \mathrm{~S}$ from a gas mixture e.g. hydrogen fermentation raw gas. However, compared to our recent results on similar PDMS membrane module [11], it can be pointed out that the peak binary gas (90 vol.\% $\mathrm{CO}_{2}, 10$ vol.\% $\mathrm{H}_{2}$; temperature: $23{ }^{\circ} \mathrm{C}$; transmembrane pressure difference: $80 \mathrm{kPa}$ ) $\mathrm{CO}_{2} / \mathrm{H}_{2}$ selectivity (5.8) fairly exceeded the highest one (3.7) obtained in this investigation with real fermentation gases. This difference between the results is likely accountable - at least in part - to the challenging task of biohydrogen separation since biotechnological hydrogen formation is accompanied by the release of other gases that potentially demonstrate remarkable effect. Although quantifying the impact of trace compounds (present with 1.7 vol.\% concentration) in the complex biological mixture utilized to feed the PDMS membrane was beyond the scope of this study, the results proved that hydrogen upgrading was possible from raw fermentation gaseous matrice. Nevertheless, experiments will be designed to further elaborate and reveal the influence of certain impurities such as hydrogen sulfide on the separation performance of the PDMS module employed. 


\section{Conclusions}

This work demonstrated parallel biohydrogen production and separation in a doublemembrane bioreactor. When a microfiltration membrane was attached to the hydrogen fermenter it could be observed that altered hydraulic retention times significantly affected both hydrogen productivities and yields, however, in a reverse manner. Moreover, HRT has also noticeably influenced the dry matter rejection capability of the microfiltration module. The membrane bioreactor system equipped with an integrated gas separation system indicated that a commercially-established PDMS membrane possessed good potential for real case biohydrogen separation from bioreactor off-gas. This is of significance, since membranes are hardly tested under real separation conditions.

\section{Acknowledgements}

Péter Bakonyi thanks the TÁMOP 4.2.4.A/2-11-1-2012-0001 'National Excellence Program' supported by the European Union and the State of Hungary, co-financed by the European Social Fund. Nándor Nemestóthy thanks the János Bolyai Research Scholarship of the Hungarian Academy of Sciences. The financial support of DGAPA-UNAM (PAPIIT IT100113) is acknowledged. 


\section{References}

[1] Bakonyi P, Nemestóthy N, Simon V, Bélafi-Bakó K. Review on the start-up experiences of continuous fermentative hydrogen producing bioreactors. Renew Sust Energ Rev 2014;40:806-813

[2] Jung KW, Kim DH, Kim SH, Shin HS. Bioreactor design for continuous dark fermentative hydrogen production. Bioresour Technol 2011;102:8612-20

[3] Bakonyi P, Nemestóthy N, Simon V, Bélafi-Bakó K. Fermentative hydrogen production in anaerobic membrane bioreactors: A review. Bioresour Technol 2014;156:357-63

[4] Bakonyi P, Nemestóthy N, Bélafi-Bakó K. Biohydrogen purification by membranes: An overview on the operational conditions affecting the performance of non-porous, polymeric and ionic liquid based gas separation membranes. Int J Hydrogen Energy 2013;38:9673-87

[5] Oh SE, Iyer P, Bruns MA, Logan BE. Biological hydrogen production using a membrane bioreactor. Biotechnol Bioeng 2004;87:119-27

[6] Lee KS, Lin PJ, Fangchiang K, Chang JS. Continuous hydrogen production by anaerobic mixed microflora using a hollow-fiber microfiltration membrane bioreactor. Int $\mathbf{J}$ Hydrogen Energy 2007;32:950-7

[7] Shen L, Bagley DM, Liss SN. Effect of organic loading rate on fermentative hydrogen production from continuous stirred tank and membrane bioreactors. Int J Hydrogen Energy 2009;34:3689-96

[8] Lee DY, Li YY, Noike T. Continuous $\mathrm{H}_{2}$ production by anaerobic mixed microflora in membrane bioreactor. Bioresour Technol 2009;100:690-5

[9] Lee DY, Li YY, Noike T. Influence of solids retention time on continuous $\mathrm{H}_{2}$ production using membrane bioreactor. Int J Hydrogen Energy 2010;35:52-60.

[10] Kim MS, Lee DY, Kim DH. Continuous hydrogen production from tofu processing waste using anaerobic mixed microflora under thermophilic conditions. Int $\mathbf{J}$ Hydrogen Energy 2011;36:8712-8.

[11] Ramírez-Morales JE, Tapia-Venegas E, Nemestóthy N, Bakonyi P, Bélafi-Bakó K, RuizFilippi G. Evaluation of two gas membrane modules for fermentative hydrogen separation. Int J Hydrogen Energy 2013;38:14042-52. 
[12] Bakonyi P, Kumar G, Nemestóthy N, Lin CY, Bélafi-Bakó K. Biohydrogen purification using a commercial polyimide membrane module: studying the effects of some process variables. Int J Hydrogen Energy 2013;38:15092-9

[13] Bakonyi P, Borza B, Orlovits K, Simon V, Nemestóthy N, Bélafi-Bakó K. Fermentative hydrogen production by conventionally and unconventionally heat pretreated seed cultures: a comparative assessment. Int J Hydrogen Energy 2014;39:5589-96

[14] Bakonyi P, Nemestóthy N, Ramirez J, Ruiz-Filippi G, Bélafi-Bakó K. Escherichia coli (XL1-BLUE) for continuous fermentation of $\mathrm{bioH}_{2}$ and its separation by polyimide membrane. Int J Hydrogen 2012;37:5623-30

[15] Bakonyi P, Nemestóthy N, Lövitusz É, Bélafi-Bakó K. Application of Plackett-Burman experimental design to optimize biohydrogen fermentation by E. coli (XL1-BLUE). Int J Hydrogen Energy 2011;36:13949-54

[16] APHA. Standard methods for the examination of water and wastewater. $19^{\text {th }}$ ed. New York, USA: American Public Health Association; 1995

[17] Wang J, Wan W. Factors influencing fermentative hydrogen production: a review. Int J Hydrogen Energy 2009;34:799-811

[18] White CM, Steeper RR, Lutz AE. The hydrogen-fueled internal combustion engine: a technical review. Int J Hydrogen Energy 2006;31:1292-305

[19] Peighambardoust SJ, Rowshanzamir S, Amjadi M. Review of the proton exchange membranes for fuel cell applications. Int J Hydrogen Energy 2010;35:9349-84

[20] Shao L, Low BT, Chung TS, Greenberg AR. Polymeric membranes for the hydrogen economy: Contemporary approches and prospects for the future. J Membr Sci 2009;327:18-31

[21] Scholes CA, Stevens GW, Kentish SE. The effect of hydrogen sulfide, carbon monoxide and water on the performance of a PDMS membrane in carbon dioxide/nitrogen separation. $\mathrm{J}$ Membr Sci 2010;350:189-199

[22] Barillas MK, Enick RM, O’Brien M, Perry R, Luebke DR, Morreale BD. The $\mathrm{CO}_{2}$ permeability and mixed gas $\mathrm{CO}_{2} / \mathrm{H}_{2}$ selectivity of membranes composed of $\mathrm{CO}_{2}$-philic polymers. J Membr Sci 2011;372:29-39. 
[23] Merkel TC, Gupta RP, Turk BS, Freeman BD. Mixed-gas permeation of syngas components in poly(dimethylsiloxane) and poly(1-trimethylsilyl-1-propyne) at elevated temperatures. J Membr Sci 2001;191:85-94 


\section{Figure and Table captions}

Fig. 1 - The schematic chart of the double-membrane bioreactor system

1: substrate tank; 2: feed pump; 3: bioreactor; 4: strirrer; 5: PC; 6: data acquisition card; 7: BluenSens $\mathrm{H}_{2}$ sensor; 8: gas counter; 9: retentate circulation pump; 10: microfiltration membrane; 11: gas bag; 12: check valve; 13: gas (feed) sampling; 14: compressing pump; 15: pressure regulator; 16: PDMS membrane; 17: needle valve; 18: gas (retentate) sampling; 19: gas (permeate) sampling; 20: permeate side bubble meter; 21: retentate side bubble meter

Fig. 2 - Hydrogen yield and productivity as a function of hydraulic retention time Columns: blue $-\mathrm{H}_{2}$ productivity, red $-\mathrm{H}_{2}$ yield;

Fig. 3 - TS rejection of microfiltration membrane at different hydraulic detention times of the bioreactor

Columns: blue - TS concentration in the reactor; red - TS concentration in the permeate; green - TS rejection

Fig. 4 - Permeate and retentate side $\mathrm{CO}_{2}$ and $\mathrm{H}_{2}$ concentrations at various recoveries

Columns: blue $-\mathrm{CO}_{2}$, permeate; red $-\mathrm{CO}_{2}$, retentate; green $-\mathrm{H}_{2}$, permeate; purple $-\mathrm{H}_{2}$, retentate

Fig. 5 - $\mathrm{CO}_{2}$ and $\mathrm{H}_{2}$ permeabilities at various recoveries

Columns: blue $-\mathrm{CO}_{2}$; red $-\mathrm{H}_{2}$

Fig. 6 - Response of PDMS membrane performance to various recoveries

Table 1 - Projection of PDMS membrane performance to the literature 
Fig. 1

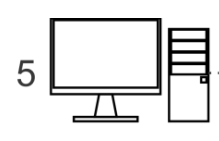

6
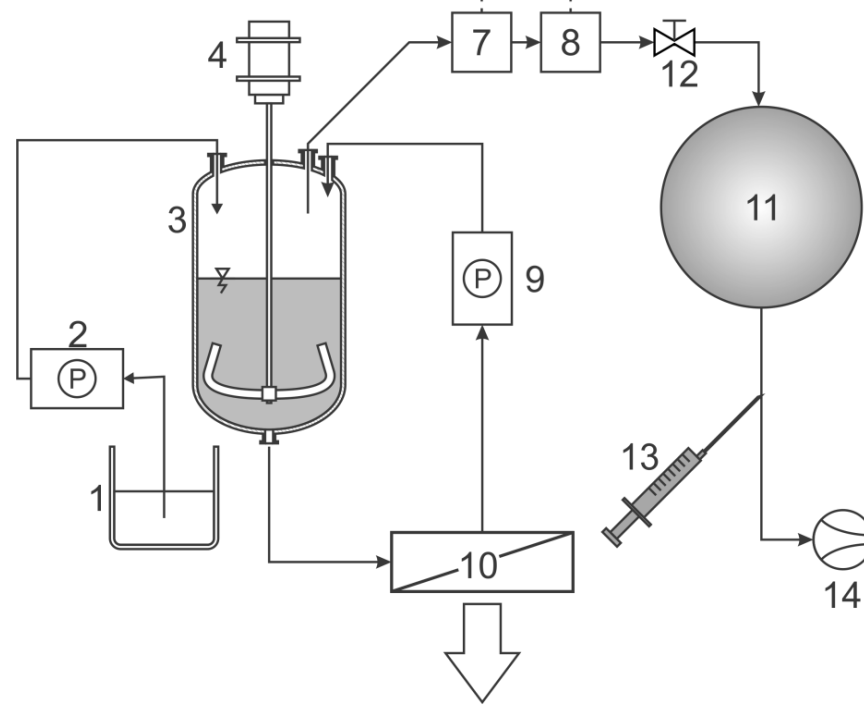

permeate 
Fig. 2

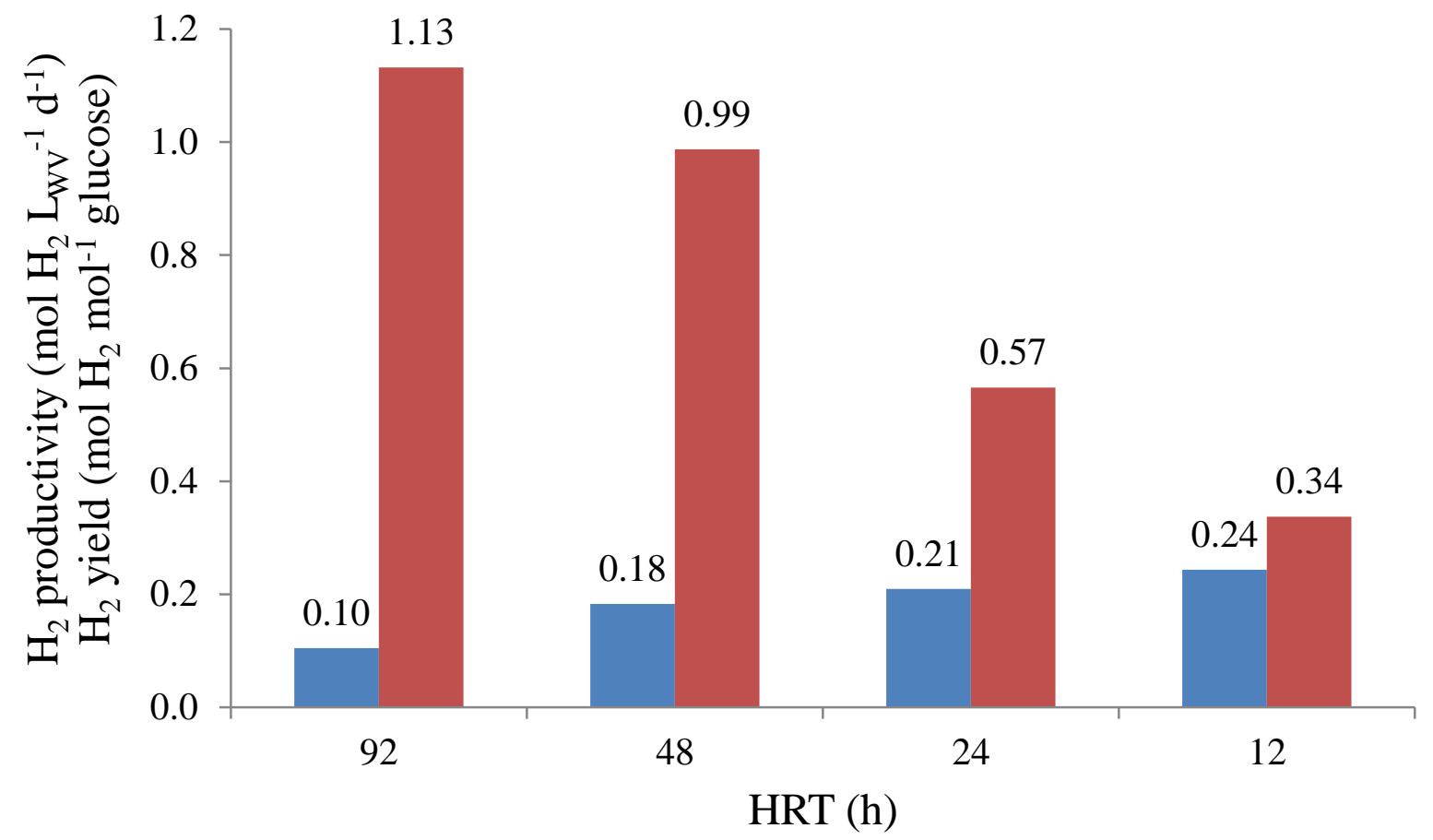


Fig. 3

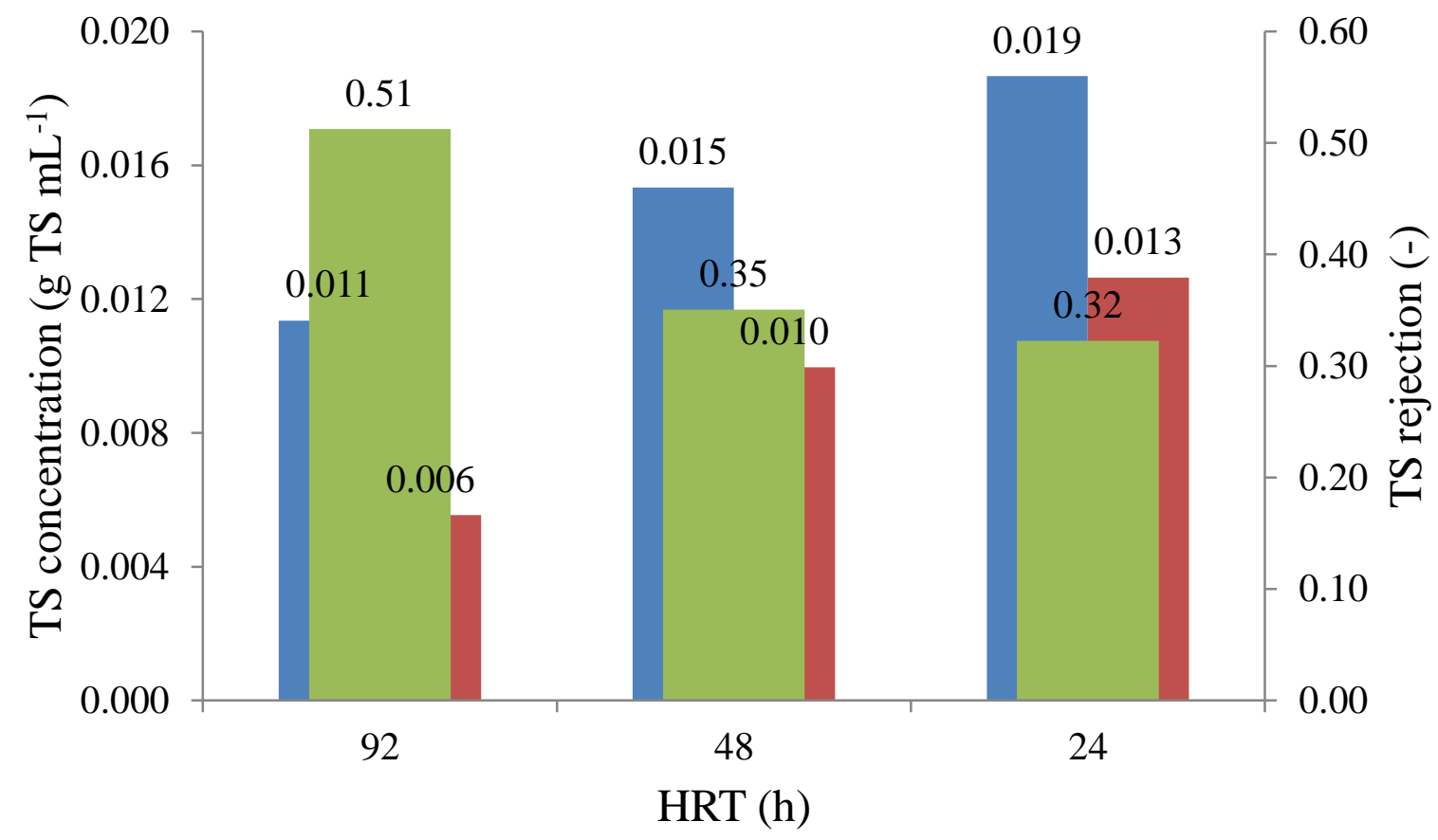


Fig. 4

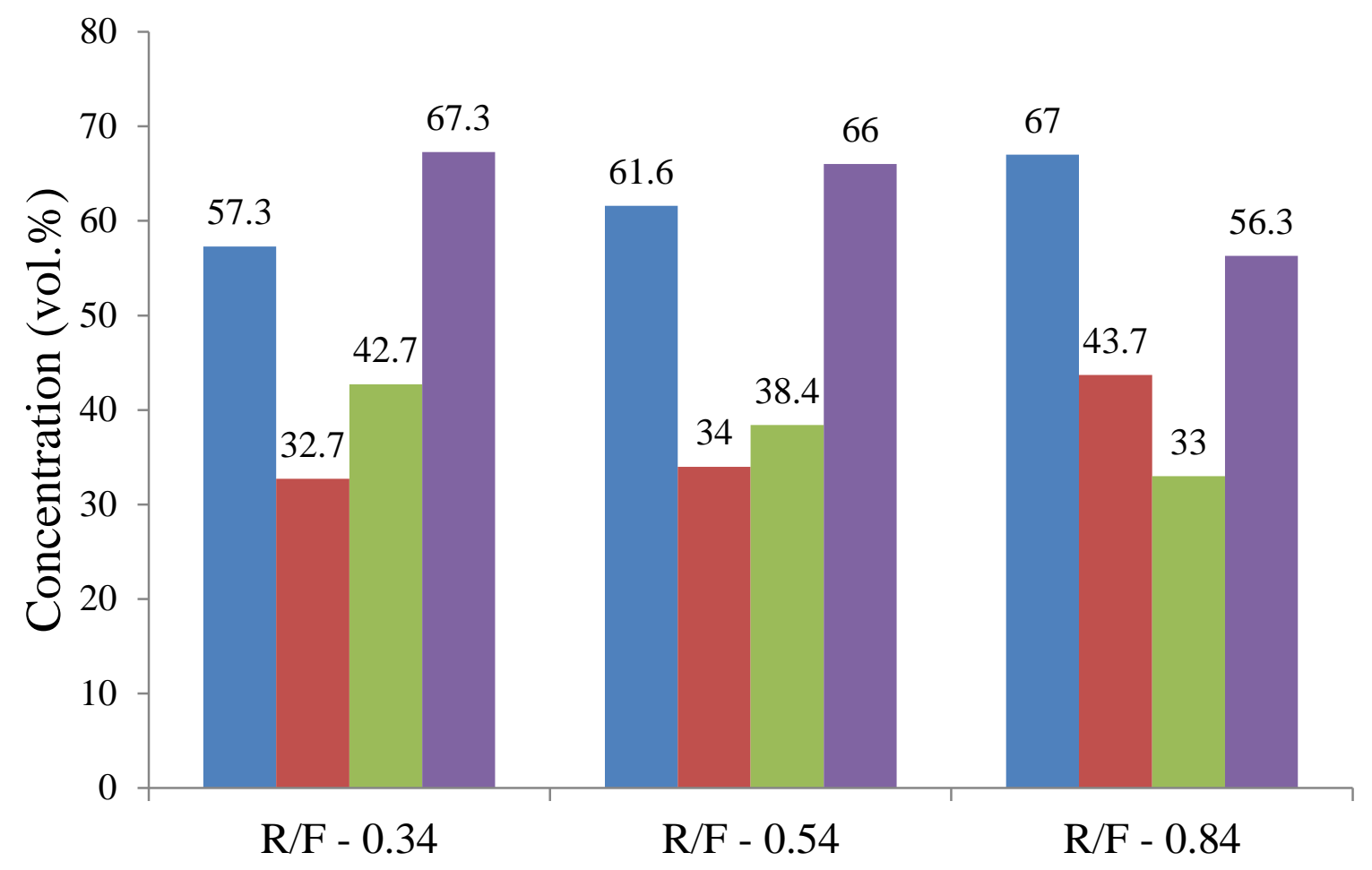


Fig. 5

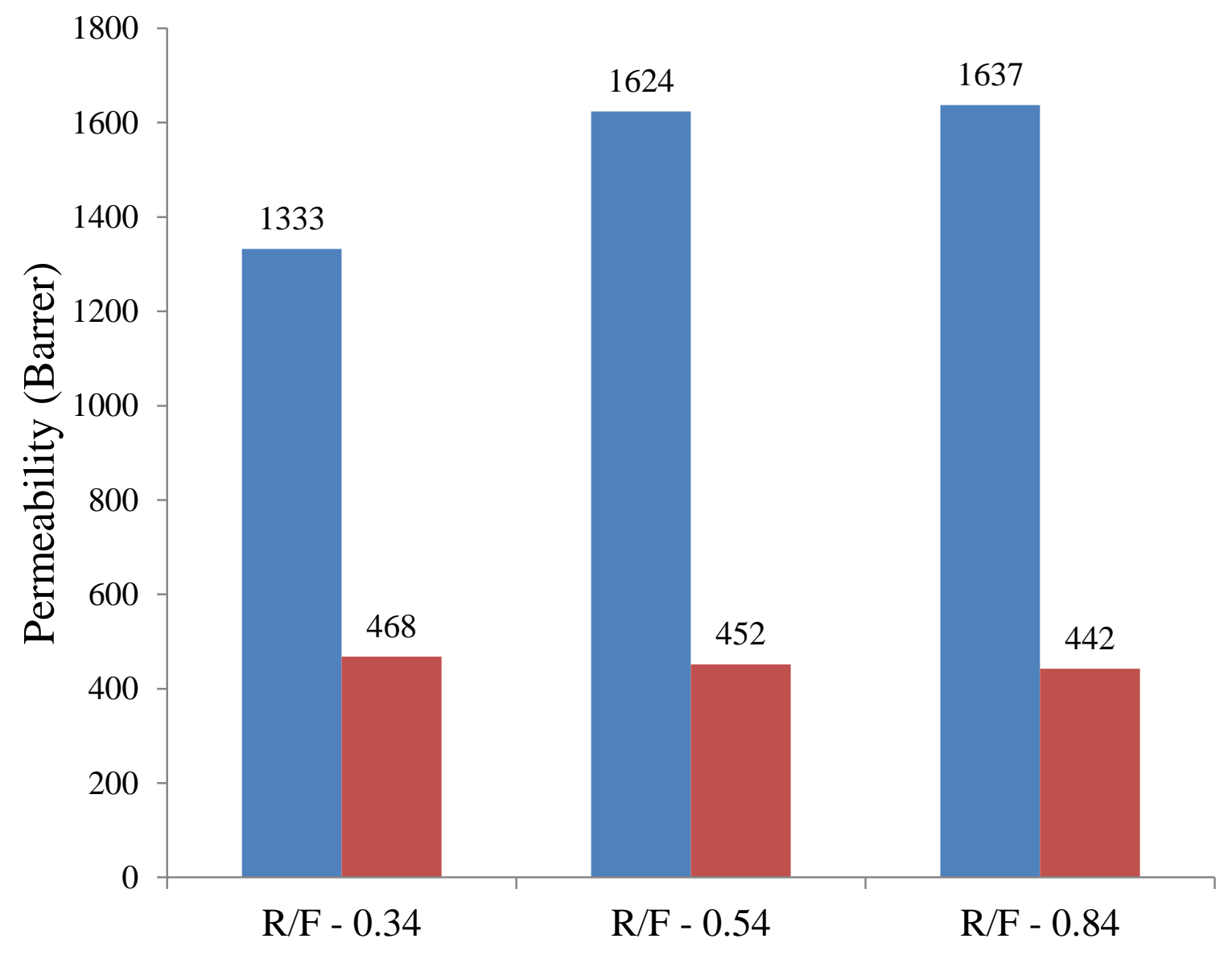


Fig. 6

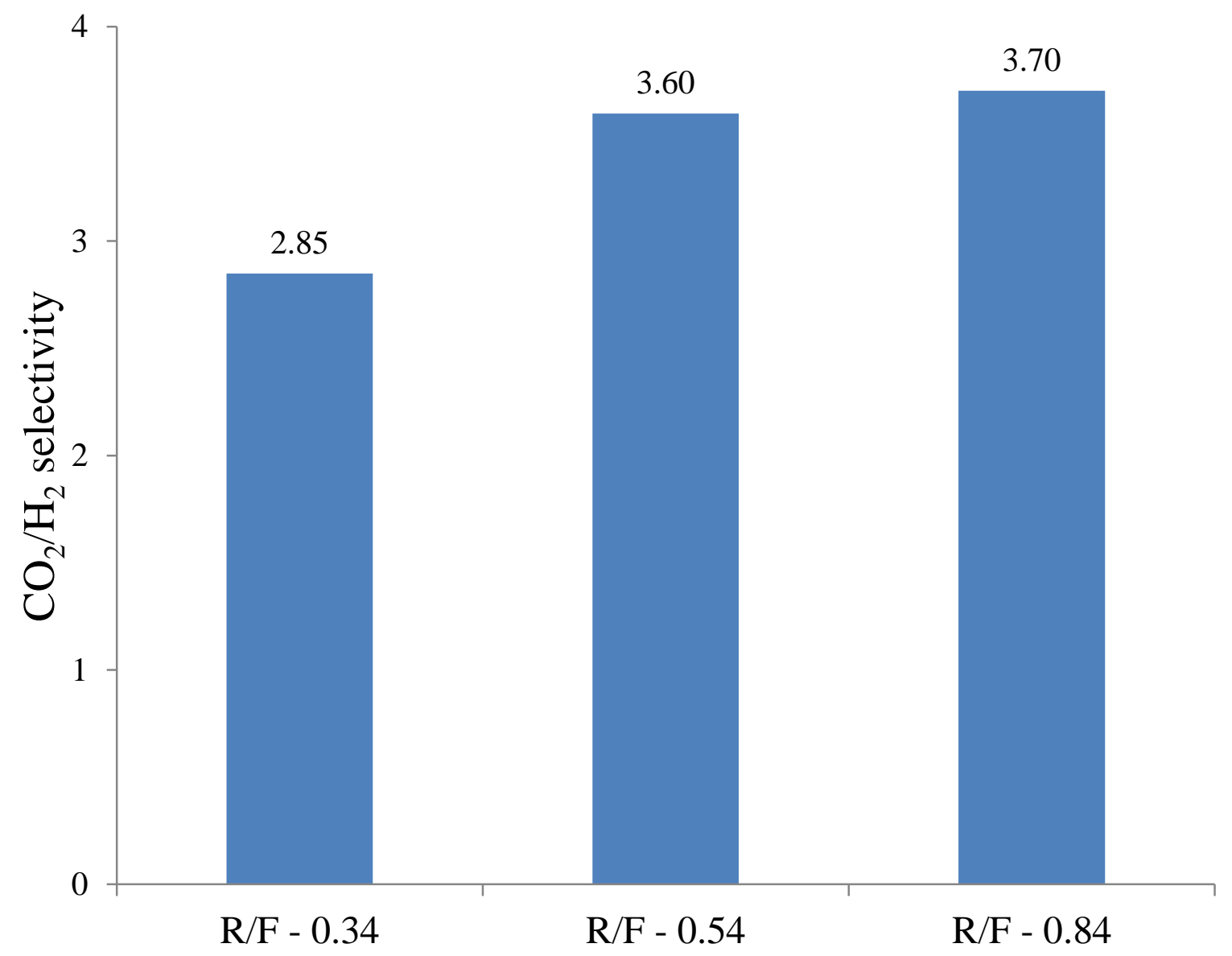


Table 1

\begin{tabular}{|c|c|c|c|c|c|c|}
\hline $\begin{array}{l}\text { Membrane } \\
\text { material }\end{array}$ & Temperature & $\begin{array}{l}\text { Feed } \\
\text { pressure }\end{array}$ & Feed gas composition & \multicolumn{2}{|c|}{ Selectivity } & Reference \\
\hline & & & & $\mathrm{H}_{2} / \mathrm{CO}_{2}$ & $\mathrm{CO}_{2} / \mathrm{H}_{2}$ & \\
\hline Polyimide & $55^{\circ} \mathrm{C}$ & 2.2 bar & 65 vol. $\% \mathrm{H}_{2}, 35$ vol. $\% \mathrm{CO}_{2}$ & 1.62 & - & {$[12]$} \\
\hline SAPO 34 & $23{ }^{\circ} \mathrm{C}$ & $1.2 \mathrm{bar}$ & 10 vol. $\% \mathrm{H}_{2}, 90$ vol. $\% \mathrm{CO}_{2}$ & - & 1.68 & {$[11]$} \\
\hline PDMS & $23{ }^{\circ} \mathrm{C}$ & 1.8 bar & 10 vol. $\% \mathrm{H}_{2}, 90$ vol. $\% \mathrm{CO}_{2}$ & - & 5.8 & [11] \\
\hline PDMS & $37{ }^{\circ} \mathrm{C}$ & N.A. & $\begin{array}{c}20 \text { vol. } \% \mathrm{H}_{2}, 20 \text { vol. } \% \mathrm{CO}_{2}, \\
\text { balance } \mathrm{Ar}\end{array}$ & - & 3.5 & {$[22]$} \\
\hline PDMS & $23{ }^{\circ} \mathrm{C}$ & $1.38 \mathrm{bar}$ & $\begin{array}{c}42 \% \text { vol. } \% \mathrm{H}_{2}, 10.5 \text { vol. } \% \\
\mathrm{CO}_{2}, 1.5 \text { vol. } \% \mathrm{H}_{2} \mathrm{~S}, 46 \% \\
\text { vol. } \% \mathrm{CO}\end{array}$ & - & 3.36 & {$[23]$} \\
\hline PDMS & $25^{\circ} \mathrm{C}$ & 3 bar & $\begin{array}{c}51.3 \text { vol. } \% \mathrm{H}_{2}, 47 \text { vol. } \% \mathrm{CO}_{2} \\
1.7 \text { vol. } \% \text { unknown trace } \\
\text { gases }\end{array}$ & - & 3.7 & [This study] \\
\hline
\end{tabular}

N.A.: Not available 